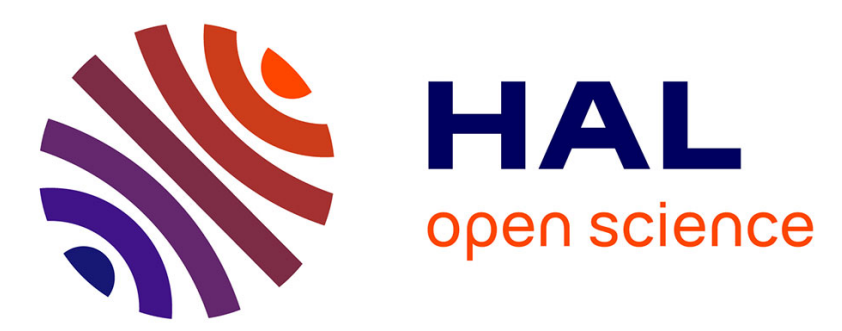

\title{
Optimal Trading for an Informed Seller
}

\author{
Anastasios Dosis
}

\section{To cite this version:}

Anastasios Dosis. Optimal Trading for an Informed Seller. 2019. hal-02130450

\section{HAL Id: hal-02130450 \\ https://essec.hal.science/hal-02130450}

Preprint submitted on 15 May 2019

HAL is a multi-disciplinary open access archive for the deposit and dissemination of scientific research documents, whether they are published or not. The documents may come from teaching and research institutions in France or abroad, or from public or private research centers.
L'archive ouverte pluridisciplinaire HAL, est destinée au dépôt et à la diffusion de documents scientifiques de niveau recherche, publiés ou non, émanant des établissements d'enseignement et de recherche français ou étrangers, des laboratoires publics ou privés. 


\section{ESSEC BUSINESS SCHOOL}

\section{OPTIMAL TRADING FOR AN INFORMED SELLER}

RESEARCH CENTER

ANASTASIOS DOSIS

ESSEC WORKING PAPER 1904

MARCH 2019

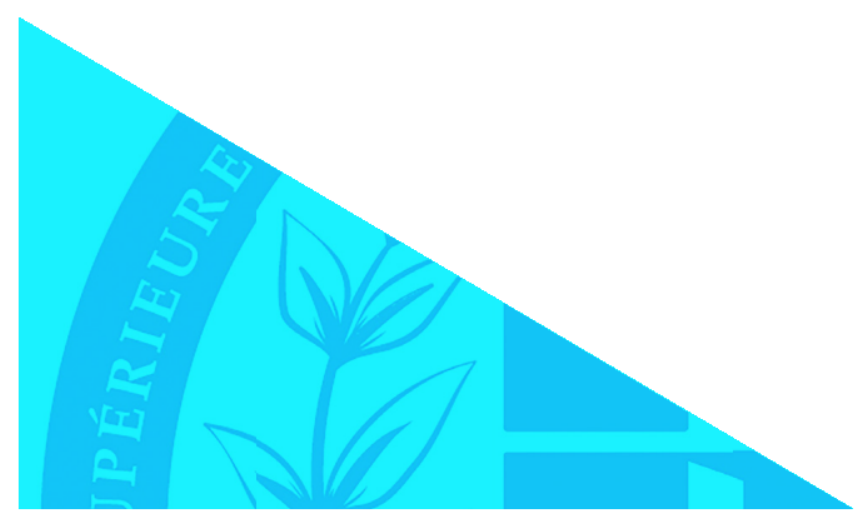




\title{
Optimal Trading for an Informed Seller
}

\author{
Anastasios Dosis*
}

March 9, 2019

\begin{abstract}
A seller with perfect monopoly power trades an indivisible object with a buyer. Both the seller's and the buyer's valuations for the object depend on its quality, which is privately known by the seller. Moreover, the seller has perfect information about the buyer's valuation for each quality. Even though posting a fixed price is ex ante optimal, it might not be interim individually rational and hence not necessarily implementable. The set of interim optimal allocations is characterised by solving a parametric linear maximisation program. These allocations might differ from simple price-posting. If the seller offers a menu of contracts, then allocations that are not interim optimal can be supported as equilibrium allocations. However, this sub-optimality result seems not to be robust if there are at least two buyers who can counter-offer menus of contracts after the seller's offer. In that case, an allocation is an equilibrium allocation if and only if it is interim optimal.
\end{abstract}

KEYWORDS: Informed seller, common values, interim optimal trading

JEL CLASSIFICATION: D82, D86

\section{INTRODUCTION}

A seller wishes to sell an indivisible object to a potential buyer. When the seller has no private information about the quality of the object, posting a fixed price is profit-maximising. This result holds even when the buyer's valuation for the object is unknown to the seller. To find the optimal price, the seller simply trades-off the expected revenue from selling the object to the probability of not selling the object at all (see Myerson (1981), Riley and Zeckhauser (1983) and Bulow and Roberts (1989)).

*Department of Economics - ESSEC Business School and THEMA, 3 Av. Bernard Hirsch, B.P. 50105, Cergy, 95021, France, Email: dosis@essec.com. 
Yilankaya (1999) shows that price-posting remains optimal even if the seller has private information about her own valuation of the object so long as this information does not directly affect the buyer's valuation for the object, i.e., private values. A natural question that arises is how these results change when the quality of the object is known to the seller but unknown to the buyer.

To study this question, I start from the simplest possible environment of bilateral trade. I consider a seller of an indivisible object who knows both the quality of the object as well as the valuation of the buyer about each quality as in Myerson (1983a) and Samuelson (1984). ${ }^{1}$ There are gains from trade for all possible qualities and the seller acts as a monopolist. Even in this simplest possible case, the question of how the seller can optimally sell the object is far from trivial. This is because both the seller's as well as the buyer's valuations for the object depend on its quality. This should be contrasted with the study of Tisljar (2003) as well as the more recent studies of Koessler and Skreta (2014) and Balestrieri and Izmalkov (2016) (see related literature), in which the seller cares only about her revenue. In fact, a first observation is that the ex ante optimal mechanism for the seller is indeed to post a fixed price and trade with probability one, irrespectively of the realisation of her type tomorrow. Nonetheless, this mechanism is not necessarily implementable because it is not always interim individually rational for some types. In other words, some high-quality types might prefer not to trade at all at the interim stage as in Akerlof (1970). Instead, these types would rather set a participation fee (price) and a probability that the object is transferred to the buyer after the latter pays the participation fee as in Myerson (1981), Myerson and Satterthwaite (1983), Cremer and McLean (1988). Such random trading contracts introduce a trade-off for the different types of the seller. Higher types can select a lower price-probability ratio than lower types because they are more willing to keep the object. Evidently, this trade-off vanishes when the seller cares only about revenue and does not derive any utility from consuming the object.

I first examine a game in which the seller makes a take-it-or-leave-it offer of a mechanism to the buyer. Such a game has been studied in Maskin and Tirole (1992).

\footnotetext{
${ }^{1}$ See also Myerson (2013) p. 489 or Mas-Colell et al. (1995) p. 906. for numerical examples of such environments.
} 
Maskin and Tirole (1992) show that: (i) the lowest bound in the payoff of all types is that from the least-cost separating (LCS) allocation (Proposition 5, p. 18), and (ii) when the LCS allocation is not interim optimal (IO), any allocation that weakly dominates it can be sustained as an equilibrium allocation (Theorem 1, p. 19).

In the last part of the paper, I show that this sub-optimality is a cutting-edge result. For, it seems not to be robust if there are at least two potential buyers and each buyer can make counter-offers of mechanisms after the seller makes her offer as in Dosis (2018). Under this modification, even if the LCS mechanism is not IO, a mechanism is an equilibrium mechanism if and only if it is IO and weakly dominates the LCS mechanism. This result is relatively intuitive. Suppose that the seller has made an offer of a mechanism that is not IO and is unable to deviate, as in Maskin and Tirole (1992), because both buyers would infer that the deviation comes from a low quality seller and would therefore reject the offer. Allowing the buyers to make counter-offers of mechanisms solves this problem. In particular, even if the seller is unable to deviate, one of the buyers always has an incentive to do so. Therefore, a necessary condition for an equilibrium mechanism is that it be IO. As shown in Dosis (2018), key to the existence of a pure strategy equilibrium is that the seller's offer remains active even after the two buyers make their offers.

The remainder of the article is organised as follows. In Section 2, I describe the model and the set of feasible allocations. I also characterise the ex ante optimal allocation for the seller and the LCS allocation and the set of IO allocations. In Section 3, I provide the set of equilibrium allocations in the simple extensive-form game studied in Maskin and Tirole (1992). In Section 4, I study a game that proposed in Dosis (2018) in which there are at least two symmetric buyers who can make counter-offers and show that the set of equilibrium allocations includes only IO allocations.

\section{THE MODEL}

- Agents. Consider a seller of an indivisible object. The object has quality $i=$ $1,2, \ldots, n$, which is privately observed by the seller. The value of a quality- $i$ object for the seller is $v_{i}^{S}$, where $0<v_{1}^{S}<v_{2}^{S}<\ldots<v_{n}^{S}$. There are two symmetric buyers, 


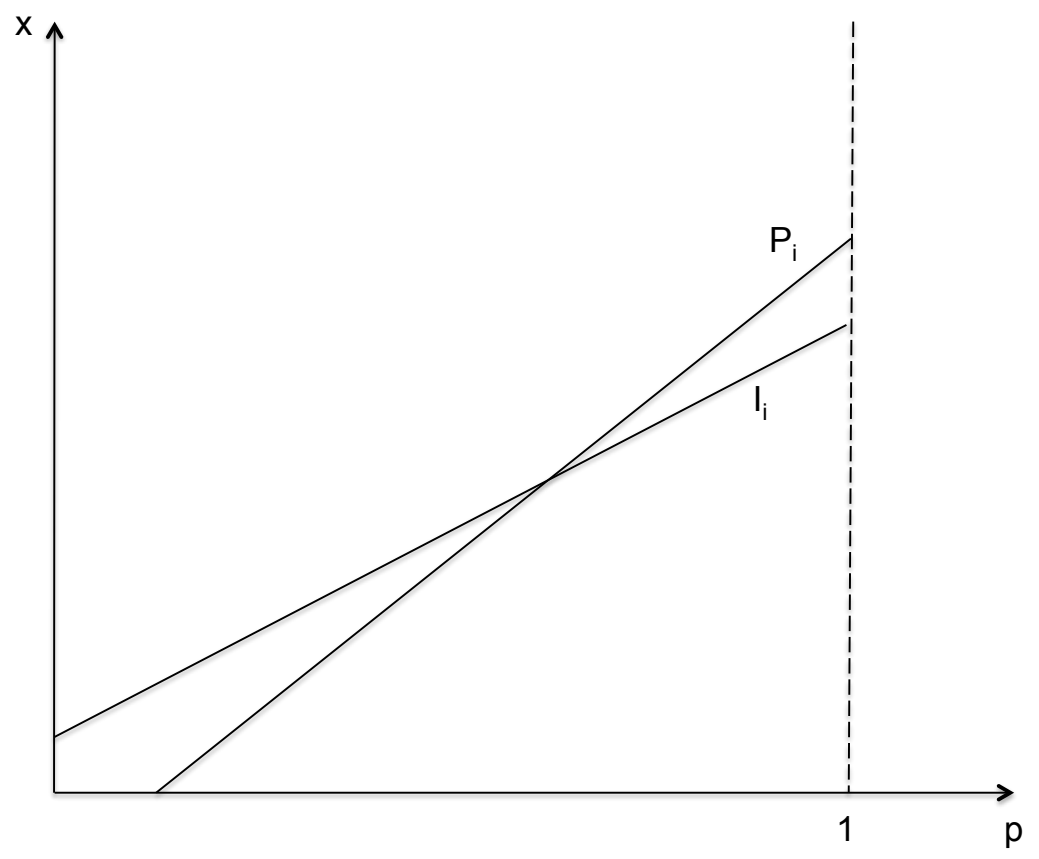

Figure 1: Representative indifference curves for the seller and a buyer. $I_{i}$ is a representative indifference curve for a seller of type- $i$ and $P_{i}$ a representative indifference curve of a buyer when trading with a seller of type- $i$.

$B=B_{1}, B_{2}$, interested in acquiring the object. ${ }^{2}$ The buyers' valuations of the object are known to the seller and for a quality- $i$ object are $v_{i}^{B_{1}}=v_{i}^{B_{2}}=v_{i}^{B}$ for every $i$, and $0<v_{1}^{B}<v_{2}^{B}<\ldots<v_{n}^{B}$. Both buyers believe that the object is of quality- $i$ with probability $q_{i}$, where $\sum_{i} q_{i}=1$. I assume that there are gains from trade for all possible qualities. Formally, $v_{i}^{S}<v_{i}^{B}$ for every $i$.

Contracts and Allocations. A contract $(x, p)$ specifies a participation fee $(x)$ and a probability $(p)$ that the seller transfers the object to a buyer. Let $\mathcal{Y}=\mathbb{R}_{+} \times[0,1]$ denote the space of feasible contracts. The payoff of type $i$ from contract $(x, p)$ is $x+(1-p) v_{i}^{S}$, whereas this of the buyer is $-x+p v_{i}^{B}$.

The indifference curves for the seller and a buyer can be represented in the $p-x$ space as upward-slopping lines. Such indifference curves are depicted in Figure 1. The slope of an indifference curve for the buyer is higher than this of the seller.

An allocation $\left(\left(x_{i}, p_{i}\right)\right)_{i}$ is a vector of contracts indexed by the set of types. An

\footnotetext{
${ }^{2}$ For convenience, I use feminine pronouns for the seller and masculine pronouns for the buyers.
} 
allocation is incentive compatible (IC) if and only if every type prefers to announce the true quality of the object, or formally:

Definition 2.1. An allocation $\left(\left(x_{i}, p_{i}\right)\right)_{i}$ is IC if and only if $x_{i}+\left(1-p_{i}\right) v_{i}^{S} \geq x_{i^{\prime}}+\left(1-p_{i^{\prime}}\right) v_{i}^{S}$ for every $i, i^{\prime}$.

\section{The Ex ante Optimal Allocation}

The ex ante optimal allocation maximises the expected payoff of the seller before she learns her type. The ex ante optimal allocation can be found by solving the following maximisation program:

$$
\begin{aligned}
& \text { Program EO: } \max _{\left(\left(x_{i}, p_{i}\right)\right)_{i} \in \mathcal{Y}^{n}} \sum_{i} q_{i}\left(x_{i}+\left(1-p_{i}\right) v_{i}^{S}\right) \quad \text { subject to } \\
& \left(\left(x_{i}, p_{i}\right)\right)_{i} \text { is IC } \\
& \sum_{i} q_{i}\left(-x_{i}+p_{i} v_{i}^{B}\right) \geq 0
\end{aligned}
$$

Constraint (1) is the ex ante participation constraint for the buyer. It states that without any information update, the buyer is no worse off by participating. One can establish the following result:

Proposition 3.1. The ex ante optimal mechanism is for all types to post the same price $\bar{x}=\sum_{i} q_{i} v_{i}^{B}$ and trade with probability one.

Proof. Evidently, Constraint (1) is binding at the optimum. If not, then the seller can infinitesimally increase the price for all types by the same amount. The new allocation is IC. Constraint (1) can be re-written as:

$$
\sum_{i} q_{i} x_{i}=\sum_{i} q_{i} v_{i}^{B}
$$

Substituting this in the objective function the maximisation program becomes:

$$
\max _{\left(\left(x_{i}, p_{i}\right)\right)_{i} \in \mathcal{Y}^{n}} \sum_{i} q_{i} v_{i}^{S}+\sum_{i} q_{i} p_{i}\left(v_{i}^{B}-v_{i}^{S}\right) \quad \text { subject to }
$$




$$
\left(\left(x_{i}, p_{i}\right)\right)_{i} \text { is IC }
$$

Because $v_{i}^{B}>v_{i}^{S}$ for every $i$, this is strictly increasing in $p_{i}$ for every $i$. Therefore, $p_{i}=1$ for every $i$. But then the only incentive compatible mechanism is the one in which all types ask the same price $\bar{x}=\sum_{i} q_{i} v_{i}^{B}$.

Even though the ex ante optimal mechanism is for all types to post the same price, this might not be interim individually rational. To see this, assume that $n=2$, i.e., there are two possible types. The result straightforwardly extends to $n>2$. The ex ante optimal price for the seller is $\bar{x}=q_{1} v_{1}^{B}+q_{2} v_{2}^{B}$. However, nothing prevents this to be strictly less than $v_{2}^{S}$. This result is similar to the classic lemons problem highlighted in Akerlof (1970).

\section{The Least-Cost Separating ANd Interim Optimal Allocations}

One of the benchmark incentive-compatible allocations is known as the least-cost separating (LCS) allocation. This allocation occupies a prominent position in seminal studies of markets with asymmetric information such as Spence (1973), Rothschild and Stiglitz (1976), Wilson (1977), and Riley (1979). It is formally defined as follows.

Definition 4.1. The LCS allocation is denoted as $\left(\left(\hat{x}_{i}, \hat{p}_{i}\right)\right)_{i}$ and satisfies the following conditions:

$$
\hat{x}_{1}=v_{1}^{B}, \hat{p}_{1}=1
$$

and for every $i=2, \ldots, n$,

$$
\begin{aligned}
& \hat{x}_{i-1}+\left(1-\hat{p}_{i-1}\right) v_{i-1}^{S}=\hat{x}_{i}+\left(1-\hat{p}_{i}\right) v_{i-1}^{S} \\
& \hat{x}_{i}=\hat{p}_{i} v_{i}^{B}
\end{aligned}
$$

In the LCS allocation, there is no distortion for the lowest type (Eq. (2)). For all other types, the price and probability of trade are distorted downwards (Eqs. (3) and (4)). The LCS allocation is the allocation that maximises the payoffs of all types 


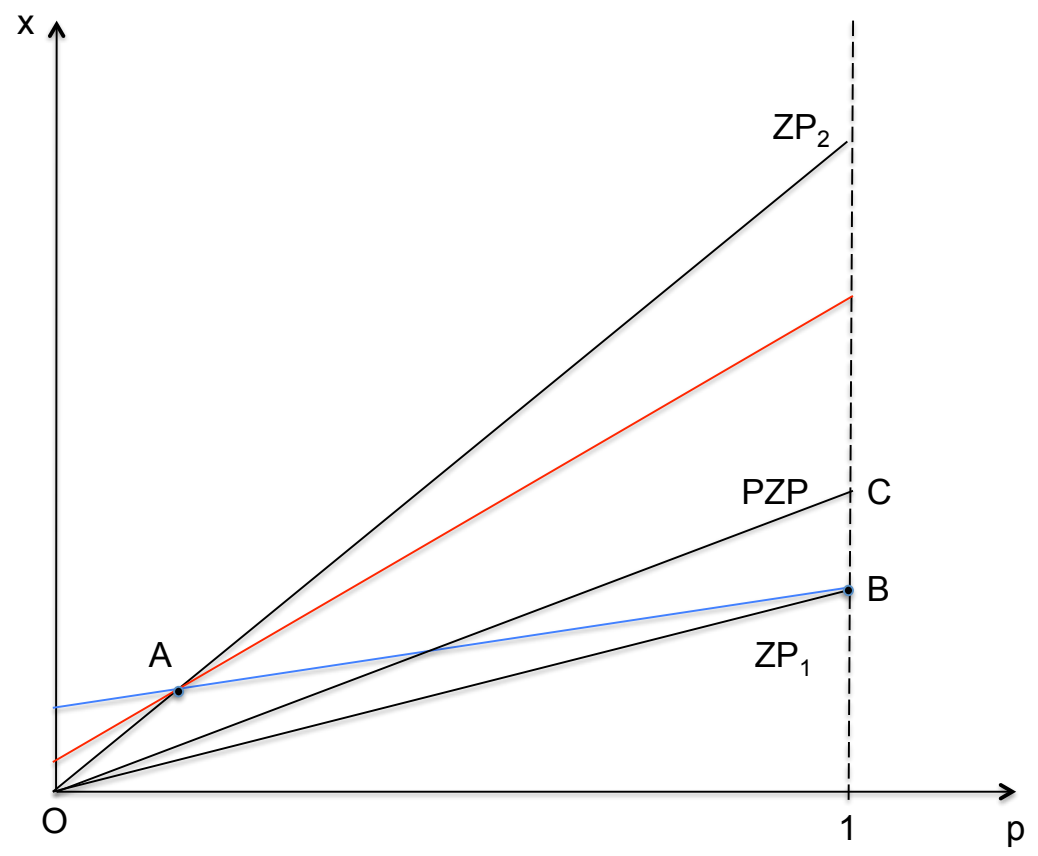

Figure 2

within the set of incentive-compatible allocations that are individually rational for the buyer, type-by-type.

The LCS allocation is depicted in Figure 2 as $(A, B)$ for the case $n=2$. In this allocation, there is no distortion for the lowest type. For all other types the price and probability of trade are distorted downwards. The LCS allocation is the allocation that maximises the payoff of all types within the set of incentive-compatible allocation that are individually rational for the buyer type by type.

A set of allocations that could be implemented by the seller even after she learns her type is the set of interim optimal (IO) allocations.

Definition 4.2. An allocation $\left(\left(p_{i}, x_{i}\right)\right)_{i}$ is IO for the seller, as defined in Holmstrom and Myerson (1983), if and only if it solves the following program:

$$
\begin{gathered}
\max _{\left(\left(x_{i}, p_{i}\right)\right)_{i} \in \mathcal{Y}^{n}} \sum_{i} w_{i}\left(x_{i}+\left(1-p_{i}\right) v_{i}^{S}\right) \quad \text { subject to } \\
\left(\left(x_{i}, p_{i}\right)\right)_{i} \text { is IC } \\
\text { (1) } \\
x_{i}-p_{i} v_{i}^{S} \geq 0
\end{gathered}
$$


Unlike Program EO, there is an extra constraint, which places a lower bound in the payoff of every type. This bound is given by the payoff that each type can achieve by consuming the object. Moreover, the weights in the objective function are not the prior beliefs about the type of the seller but rather any vector of nonnegative weights. The definition of an interim optimal allocation is similar to Maskin and Tirole (1992)'s definition of an interim efficient allocation relative to the prior beliefs (Maskin and Tirole (1992), p. 16).

\section{The Seller Offers a Menu of Contracts}

What allocations can be implemented by the seller in a noncooperative equilibrium? To study this question, suppose that the seller makes a take-it-or-leave-it offer of a menu of contracts to the buyer. Such a game is studied in Maskin and Tirole (1992). In particular, Maskin and Tirole (1992) study an extensive form game with three stages. In the first stage, the seller proposes a menu of contracts. In the second stage, each buyer accepts or rejects the proposal. If the buyer rejects, the game ends. If the buyer accepts, the game moves to the third stage. In the third stage, the seller announces a quality. Maskin and Tirole (1992) analyse in detail the (perfect Bayesian) equilibrium allocation of this three-stage game. ${ }^{3}$ For more details and formal definitions, which are omitted here, one can consult their article. The following proposition based on Maskin and Tirole (1992) characterises the set of equilibrium allocations:

Proposition 5.1 (Maskin and Tirole (1992)). An allocation $\left(\left(\tau_{i}, \pi_{i}\right)\right)_{i}$ is an equilibrium allocation if and only if (i) it is IC, (ii) satisfies Constraint (1), and, (iii) $x_{i}+\left(1-p_{i}\right) v_{i}^{S} \geq$ $\hat{x}_{i}+\left(1-\hat{p}_{i}\right) v_{i}^{S}$ for every $i$.

This proposition has two fundamental implications. First, the equilibrium of this game is unique if and only if the LCS allocation is IO. Second, if the LCS allocation is not $\mathrm{IO}$, then the set of equilibrium allocations includes allocations that are not interim IO.

\footnotetext{
${ }^{3}$ An equilibrium allocation is an allocation that results as the equilibrium outcome of the three-stage game when all players use their equilibrium strategies.
} 


\section{TWO SYMMETRIC BUYERS}

- Motivation. Suppose now that instead of one, there are two potential symmetric buyers. I show that the sub-optimality result of MT is not robust in a simple modification of the trading protocol and in particular if the two buyers are allowed to offer mechanisms after the seller offers her mechanism but before she makes a final choice. This result is very intuitive. Because the object can be consumed only by one buyer, after the seller makes an offer of a mechanism that is suboptimal, the two buyers will compete to obtain the object. As such, one will offer a better deal to the seller to win the object and hence no sub-optimal mechanism can be sustained as an equilibrium mechanism.

Game and Equilibrium. A menu of contracts is a n-tuple denoted by $m \in \mathcal{Y}^{n}$. The seller and the two buyers play the following game as studied in Dosis (2018):

STAGE 1: The seller proposes a menu of contracts.

STAGE 2: Each buyer accepts or rejects. If both buyers reject, the game ends. If at least one buyer accepts, the game moves to Stage 3 .

STAGE 3: Each buyer who accepted in Stage 2 proposes a menu of contracts.

STAGE 4: The seller selects one buyer and a contract from the menu she proposed in Stage 1 or the menu proposed by that buyer in Stage 3.

A strategy for the seller specifies a menu for every possible type in the first stage of the game and a choice of a buyer and a contract for every possible history of play in the fourth stage. A strategy for a buyer specifies a decision to accept or reject for every possible history of play in the second stage and a choice of a menu for every possible history in the third stage. A belief system specifies a probability distribution over the two types for every possible history of play (i.e., for every menu in the first stage). A pure strategy perfect Bayesian equilibrium specifies a set of strategies, one for each player, and a belief system such that (i) the strategy of each player is sequentially rational given the beliefs and (ii) the beliefs are by determined Bayes' rule (whenever possible) given the players' equilibrium strategies. For nodes that 
are not reached on-the-equilibrium path, beliefs are arbitrarily determined to support the equilibrium strategies. I consider the set of equilibrium allocations of this four-stage game. An equilibrium allocation is an allocation that results as an allocation from the players' equilibrium strategies.

Equilibrium allocations. One can then prove the following result.

Proposition 6.1. An allocation is an equilibrium allocation if and only if: (i) it is $I O$, and (ii) $x_{i}+\left(1-p_{i}\right) v_{i}^{S} \geq \hat{x}_{i}+\left(1-\hat{p}_{i}\right) v_{i}^{S}$ for every $i$.

Proof. First, consider the "only if" part. Note that the proof of Part (ii) is identical to the proof of Proposition 5 in Maskin and Tirole (1992) (p. 18) and, hence, is omitted. Due to the inscrutability principle (i.e., Myerson (1983b)), there is no loss of generality in focusing on equilibria in which all types offer the same menu in Stage 1.

For Part (i), suppose that there exists an equilibrium allocation $\left(\left(x_{i}, p_{i}\right)\right)_{i}$ that is not IO. Suppose first that $\sum_{i} q_{i}\left(-x_{i}+p_{i} v_{i}^{B}\right)>0$. It is evident that at least one buyer, say $B_{1}$, has equilibrium payoff $V_{B_{1}}<\sum_{i} q_{i}\left(-x_{i}+p_{i} v_{i}^{B}\right)$. Consider allocation $\left(\left(x_{i}+\varepsilon, p_{i}\right)\right)_{i}$. For every $i, x_{i}+\varepsilon+\left(1-p_{i}\right) v_{i}^{S}>x_{i}+\left(1-p_{i}\right) v_{i}^{S}$. Moreover, $\left(\left(x_{i}+\varepsilon, p_{i}\right)\right)_{i}$ is incentive compatible because it only increases the price in the contract of every type by $\varepsilon$. The expected payoff of a buyer from this allocation is $\sum_{i} q_{i}\left(x_{i}+p_{i} v_{i}^{B}\right)-\varepsilon$, which for a sufficiently small $\varepsilon$, is such that $V_{B_{1}}<\sum_{i} q_{i}\left(x_{i}+p_{i} v_{i}^{B}\right)-\varepsilon$. However, from the definition of equilibrium, it is true that $V_{B_{1}} \geq \sum_{i} q_{i}\left(x_{i}+p_{i} v_{i}^{B}\right)-\varepsilon$, a contradiction.

Suppose now that $\left(\left(x_{i}, p_{i}\right)\right)_{i}$ is an equilibrium allocation that is not $\mathrm{IO}$ and $\sum_{i} q_{i}\left(-x_{i}+\right.$ $\left.p_{i} v_{i}^{B}\right)=0$. The following lemma facilitates the remainder of the "only-if" proof.

Lemma 6.2. For every $\left(\left(p_{i}, x_{i}\right)\right)_{i}$ that is not IO and satisfies $\sum_{i} q_{i}\left(-x_{i}+p_{i} v_{i}^{B}\right)=0$, there exists an allocation $\left(\left(x_{i}^{\prime}, p_{i}^{\prime}\right)\right)_{i}$ such that: (i) $\sum_{i} q_{i}\left(-x_{i}^{\prime}+p_{i}^{\prime} v_{i}^{B}\right)>0$, and (ii) $x_{i}^{\prime}+\left(1-p_{i}^{\prime}\right) v_{i}^{S}>$ $x_{i}+\left(1-p_{i}\right) v_{i}^{S}$ for every $i$.

Proof. Consider allocation $\left(\left(x_{i}, p_{i}\right)\right)_{i}$ that is not IO such that $\sum_{i} q_{i}\left(-x_{i}+p_{i} v_{i}^{B}\right)=0$. By the definition of IO allocations, there exists an incentive-compatible allocation $\left(\left(\tilde{x}_{i}, \tilde{p}_{i}\right)\right)_{i}$ and a subset of types $\tilde{I} \subseteq\{1, \ldots, n\}$ such that: (i) $\sum_{i} q_{i}\left(-\tilde{x}_{i}+\tilde{p}_{i} v_{i}^{B}\right) \geq 0$, (ii) $\tilde{x}_{i}+\left(1-\tilde{p}_{i}\right) v_{i}^{S}>x_{i}+\left(1-p_{i}\right) v_{i}^{S}$ for every $i \in \tilde{I}, \tilde{x}_{i}+\left(1-\tilde{p}_{i}\right) v_{i}^{S}=x_{i}+\left(1-p_{i}\right) v_{i}^{S}$ for every $i \in\{1, \ldots, n\} / \tilde{I}$. Consider allocation $\left(\left(x_{i}^{\delta}, p_{i}^{\delta}\right)\right)_{i}$, where $x_{i}^{\delta}+\left(1-p_{i}^{\delta}\right) v_{i}^{S}=\tilde{x}_{i}+\left(1-\tilde{p}_{i}\right) v_{i}^{S}-\delta$ 
for every $i \in \tilde{I}$ and $\left(x_{i}^{\delta}, p_{i}^{\delta}\right)=\left(x_{i}, p_{i}\right)$ for every $i \in\{1, \ldots, n\} / \tilde{I}$. For a sufficiently small $\delta>0$, the following inequalities are true:

$$
\begin{gathered}
x_{i}^{\delta}+\left(1-p_{i}^{\delta}\right) v_{i}^{S}=\tilde{x}_{i}+\left(1-\tilde{p}_{i}\right) v_{i}^{S}-\delta \geq x_{j}+\left(1-p_{j}\right) v_{i}^{S}=x_{j}^{\delta}+\left(1-p_{j}^{\delta}\right) v_{i}^{S} \forall i \in \tilde{I}, j \in\{1, \ldots, n\} / \tilde{I} \\
x_{i}^{\delta}+\left(1-p_{i}^{\delta}\right) v_{i}^{S}=\tilde{x}_{i}+\left(1-\tilde{p}_{i}\right) v_{i}^{S}-\delta \geq \tilde{x}_{j}+\left(1-\tilde{p}_{j}\right) v_{i}^{S}-\delta=x_{j}^{\delta}+\left(1-p_{j}^{\delta}\right) v_{i}^{S} \forall i, j \in \tilde{I} \\
x_{i}^{\delta}+\left(1-p_{i}^{\delta}\right) v_{i}^{S}=x_{i}+\left(1-p_{i}\right) v_{i}^{S} \geq x_{j}+\left(1-p_{j}\right) v_{i}^{S}=x_{j}^{\delta}+\left(1-p_{j}^{\delta}\right) v_{i}^{S} \forall i, j \in\{1, \ldots, n\} / \tilde{I} \\
x_{i}^{\delta}+\left(1-p_{i}^{\delta}\right) v_{i}^{S}=x_{i}+\left(1-p_{i}\right) v_{i}^{S} \geq \tilde{x}_{j}+\left(1-\tilde{p}_{j}\right) v_{i}^{S}>\tilde{x}_{j}+\left(1-\tilde{p}_{j}\right) v_{i}^{S}-\delta \forall i \in\{1, \ldots, n\} / \tilde{I}, j \in \tilde{I}
\end{gathered}
$$

Thus, $\left(\left(x_{i}^{\delta}, p_{i}^{\delta}\right)\right)_{i}$ is also incentive compatible. The expected payoff of the buyer from allocation $\left(\left(x_{i}^{\delta}, p_{i}^{\delta}\right)\right)_{i}$ is $\sum_{i} \lambda_{i} u_{i}^{B}\left(x_{i}^{\delta}, p_{i}^{\delta}\right)>0$. Allocation $\left(\left(x_{i}^{\prime}, p_{i}^{\prime}\right)\right)_{i}$, where $\left(x_{i}^{\prime}, p_{i}^{\prime}\right)=$ $\left(x_{i}^{\delta}-\epsilon, p_{i}^{\delta}\right)$, is incentive compatible; it improves the payoff of all types over $\left(\left(\tilde{x}_{i}, \tilde{p}_{i}\right)\right)_{i}$, and for $\epsilon>0$ small enough it is true $\sum_{i} q_{i}\left(-x_{i}^{\prime}+p_{i}^{\prime} v_{i}^{B}\right)>0$.

If the equilibrium allocation is such that $\sum_{i} \lambda_{i}\left(-x_{i}+p_{i} v_{i}^{B}\right)=0$, both buyers have an expected payoff equal to zero. By Lemma 6.2, there exists an allocation that improves the payoff of all types and is strictly individually rational for a buyer. From the definition of equilibrium, we know that such an allocation is not possible, a contradiction.

The proof of the "if" part is constructive. Consider the following strategies and beliefs: All types offer menu $\bar{m}=\left(\left(\bar{x}_{i}, \bar{p}_{i}\right)\right)_{i^{\prime}}$ where $\left(\left(\bar{x}_{i}, \bar{p}_{i}\right)\right)_{i}$ is an IO allocation satisfying $\bar{x}_{i}+\left(1-\bar{p}_{i}\right) v_{i}^{S} \geq \hat{x}_{i}+\left(1-\hat{p}_{i}\right) v_{i}^{S}$ for every $i$, and all types contract with buyer $B_{1}$, if both buyers offer $\bar{m}$. If exactly one buyer accepts and offers a menu $\tilde{m} \neq \bar{m}$, then all types contract with this buyer. If both buyers accept and offer menus $\tilde{m}_{B_{1}}$ and $\tilde{m}_{B_{2}}$, different than $\bar{m}$, then type-i selects buyer $B$, where:

$$
\max _{(x, p) \in \tilde{m}_{B}} x+(1-p) v_{i}^{S}>\max _{(x, p) \in \tilde{m}_{-B}} x+(1-p) v_{i}^{S}
$$

The seller selects a buyer with equal probability if:

$$
\max _{(x, p) \in \tilde{m}_{B}} x+(1-p) v_{i}^{S}=\max _{(x, p) \in \tilde{m}_{-B}} x+(1-p) v_{i}^{S}
$$

Each buyer accepts and offers $\bar{m}$, unless the offer of the seller $\tilde{m} \neq \bar{m}$ is such that:

$$
\max _{(x, p) \in \tilde{m}} p+(1-x) v_{1}^{S} \geq \hat{p}_{1}+\left(1-\hat{x}_{1}\right) v_{1}^{S}
$$


If all types offer $\bar{m}$, then the posterior beliefs remain equal to the prior beliefs. For every other offer, the posterior beliefs are updated to $(1,0, \ldots 0)$, i.e., both buyers believe with certainty that type 1 is deviating.

One can easily confirm that the strategies described above constitute equilibrium strategies. Based on the beliefs held by the two buyers, no type has an incentive to deviate unilaterally. Consider a deviation. From the specification of the off-theequilibrium path beliefs, both buyers believe that the deviator has an object of the lowest quality. Therefore, the maximum payoff from a deviation is that from $\left(\hat{x}_{1}, \hat{p}_{1}\right)$. However, the payoff of all types with quality higher than type 1 is strictly higher than this payoff, and the payoff of type 1 is equal to this payoff. Therefore, the deviation is unprofitable. Now, consider a deviation by some buyer. Given that $\left(\left(\bar{x}_{i}, \bar{p}_{i}\right)\right)_{i}$ is IO, every menu that improves the payoff of at least one type is unprofitable. Suppose that it is not, i.e., suppose that some buyer deviates by offering menu $\tilde{m}$ that provides a higher payoff to only a subset of types $\tilde{I} \subseteq\{1, \ldots, n\}$ and earns a strictly positive payoff. By the specification of the equilibrium strategies, all types contract with this buyer. Consider allocation $\left(\left(x_{i}^{\prime}, p_{i}^{\prime}\right)\right)_{i}$, where: (i) $\left(x_{i}^{\prime}, p_{i}^{\prime}\right)=\left(\bar{x}_{i}, \bar{p}_{i}\right)$ for every $i \in\{1, \ldots, n\}-\tilde{I}$, and (ii) $\left(x_{i}^{\prime}, p_{i}^{\prime}\right) \in \arg \max _{(x, p) \in \tilde{m}} x+(1-p) v_{i}^{S}$ for every $i \in \tilde{I}$. Allocation $\left(\left(x_{i}^{\prime}, p_{i}^{\prime}\right)\right)_{i}$ is incentive compatible. To see this, note the following:

$$
\begin{aligned}
& \bar{x}_{i}+\left(1-\bar{p}_{i}\right) v_{i}^{S} \geq \bar{x}_{j}+\left(1-\bar{p}_{j}\right) v_{i}^{S} \quad \forall i, j \in\{1, \ldots, n\}-\tilde{I} \\
& \bar{x}_{i}+\left(1-\bar{p}_{i}\right) v_{i}^{S} \geq \max _{(x, p) \in \tilde{m}} x+(1-p) v_{i}^{S} \quad \forall i \in\{1, \ldots, n\}-\tilde{I} \\
& \max _{(x, p) \in \tilde{m}} x+(1-\bar{p}) v_{i}^{S}>\bar{x}_{i}+\left(1-\bar{p}_{i}\right) v_{i}^{S} \quad \forall i \in \tilde{I}
\end{aligned}
$$

Moreover, $\sum_{i} q_{i}\left(-x_{i}^{\prime}+p_{i}^{\prime} v_{i}^{S}\right)>0$, which contradicts that every allocation that dominates $\left(\left(\bar{x}_{i}, \bar{p}_{i}\right)\right)_{i}$ is not interim individually rational for the buyer.

\section{DisCUSSION}

- Relation to Maskin and Tirole (1992) and Dosis (2018). As I discussed in the introduction, the article is related to Maskin and Tirole (1992) and Dosis (2018). Maskin and Tirole (1992) study an extensive-form game with three stages. In the first stage, the seller proposes a mechanism. In the second stage, each buyer accepts or rejects the proposal. If both buyers reject, the game ends and all parties 
receive their reservation allocation. If at least one buyer accepts, the game moves to the third stage. In the third stage, the seller selects a buyer and implements the mechanism. ${ }^{4}$ Maskin and Tirole (1992) analyse the perfect Bayesian equilibrium allocations of this three-stage game. They show that an allocation is an equilibrium allocation if and only if it is incentive compatible and individually rational for all players and the payoff of no seller type falls bellow that from the LCS allocation. This implies that when the LCS allocation is not IO, non-IO allocations can be sustained as equilibrium allocations.

The game that analysed in Section 4 has been studied in Dosis (2018). Dosis (2018) studies stylised markets with asymmetric information, e.g., insurance markets, and shows that only interim efficient allocations can be supported as equilibrium allocations. To intuititively explain why this game eliminates every non-IO allocation from the set of equilibrium allocations, note that the existence of at least two symmetric buyers is indispensable. To see this, consider again the inefficiency result in Maskin and Tirole (1992) . This result relies on the arbitrariness in the specification of the off-the-equilibrium path beliefs. This is because if the buyers hold pessimistic beliefs about all allocations that dominate a non-IO allocation, then the seller is unable to deviate because of the fear of being rejected. This is where the addition of the stage in which the two buyers counter-offer menus proves useful. Because the seller can contract with one buyer at a time, there is implicit competition between the two buyers. Therefore, even if the seller is unable to deviate, one of the buyers has an incentive to do so. With only one buyer, there is no implicit competition and hence no profitable deviations from inefficient allocations. However, adding a stage in which the uninformed parties compete on menus of contracts may create problems regarding the existence of a pure strategy equilibrium, as highlighted in the seminal contribution of Rothschild and Stiglitz (1976). As extensively discussed in Dosis (2018), key to overcoming this existence problem is that the offer of the seller remains active even after the buyers counter-offer menus. This feature restricts the buyers' set of profitable deviations.

To clarify this point, consider a game in which the buyers simply compete in

\footnotetext{
${ }^{4}$ Maskin and Tirole (1992) consider a model with a single agent, but the results trivially extend to a model with several symmetric agents as in this article.
} 
menus of contracts without the seller making any offer. Second, consider a game in which the buyers can disregard the offer of the seller and merely offer their own menus. Neither of these games sustains a pure strategy equilibrium when the LCS allocation is not IO. As shown in the appendix, this game does not sustain a pure strategy equilibrium when the LCS allocation is not IO.This is not so when the seller makes an offer and this offer remains active. This is because, in this game, one can construct a sequentially rational strategy for the seller, as I did in the proof of Proposition 6.1, such that all types propose an IO allocation in the first stage and all types contract with any buyer who attempts to attract the most profitable types (if at all) in the last stage. Because the seller has access to her offer in the last stage of the game, no buyer can attract the most profitable types without attracting the least profitable types. In other words, the offer of the seller restricts the buyers' set of profitable deviations.

From a methodological point of view, one difference between Dosis (2018) and the environment studied in this paper is that in Dosis (2018) the informed party is strictly risk averse. Therefore, the arguments underlying the proof differ from this paper in which all parties are risk neutral. In particular, under risk aversion, one substantially relies on Jensen's inequality to construct profitable deviations.

Renegotiation. One can interpret the stage in which the buyers counter-offer menus of contracts as a renegotiation stage. A buyer has the right to "challenge" the menu offered by the seller by offering a different menu. Following the proposals of the buyers, the seller can select which menu she prefers, i.e., the one she offered or any of the menus proposed by any of the buyers (if at all). This is similar to a standard two-stage bargaining game with the first offer made by the seller.

Maskin and Tirole (1992) also define renegotiation-proof allocations (Section 6, p. 24). Renegotiation takes the form of the three-stage game as described above. ${ }^{5}$ An allocation is weakly renegotiation-proof (hereafter, WRP) if there exists an equilibrium in the renegotiation stage in which all types of the informed principal (i.e., the

\footnotetext{
${ }^{5}$ This is another way to interpret the three-stage game as stated in MT, p. 9: "...In this case, it is supposed that the parties have signed an earlier contract that leads to allocation $\mu_{0}$ and our contract proposal game can be thought of as a process of renegotiation..."
} 
seller in our case) propose this allocation. An allocation is strongly renegotiationproof (hereafter, SRP) if it is WRP and there exists no equilibrium in which the principal proposes a different allocation. It is not difficult to see that an allocation is WRP if and only if it is weakly interim efficient (Proposition 8, p. 25), whilst it is SRP only if it is interim efficient relative to the prior beliefs (Proposition 9, $p$. 25). There is a significant conceptual difference between the notions of strong renegotiation proofness in Maskin and Tirole (1992) and renegotiation in this article. Maskin and Tirole (1992) assume that there is an initial agreement (i.e., an allocation) that the two parties wish to renegotiate. The question then is which initial agreements are renegotiation-proof, i.e., there is no equilibrium in which a different allocation results as an equilibrium allocation. In this article, the initial agreement is not renegotiation-proof in the sense of Maskin and Tirole (1992), and the question is which allocations offered by the seller can survive competition on the buyers' side. Moreover, in this article, it is the uninformed parties (i.e., the buyers) who lead the renegotiation stage, as opposed to Maskin and Tirole (1992) in which it is the informed party that does so.

Related Literature. This article belongs to the long-standing literature on mechanism design by an informed principal. Myerson (1983b) formalises this problem and proceeds with an axiomatic characterisation of the selection of the mechanism by the principal. Maskin and Tirole (1990) concentrate on the noncooperative equilibria of the informed principal model with common value. With quasilinear utilities, they show that the principal neither gains nor loses from her private information. ${ }^{6}$

The article is also related to the literature studying the optimal mechanism for a seller of an indivisible object. Myerson (1981), Riley and Zeckhauser (1983) and Bulow and Roberts (1989) establish the optimality of posted prices when the seller has no private information. To find the optimal price, the seller trades-off the expected revenue from selling the object against the probability of not selling the object. Yilankaya (1999) shows that price-posting remains optimal even if the seller

\footnotetext{
${ }^{6}$ See also Tan (1996) and Skreta (2011). This information-irrelevance result is challenged in Fleckinger (2007) and more recently in Mylovanov and Tröger (2014).
} 
has private information about her own valuation of the object, as long as this information does not directly affect the buyer's valuation of the object, i.e., private values. More recently, Tisljar (2003), Koessler and Skreta (2014) and Balestrieri and Izmalkov (2016) allow the seller to have private information about the quality of the object but assume that she only maximises revenue. The latter two papers challenge the optimality of posted prices. In my model, the seller values the object and does not solely maximise revenue.

\section{CONCLUSION}

In this article I studied a model in which a seller traded an indivisible object to a buyer. I allowed the seller to have private information about the quality of the object. This quality affected both the seller's as well as the buyer's valuation for the object. I showed that the ex ante optimal mechanism induces all types to post the same price and trade with probability one. However, this mechanism may not be implementable because in some cases it is no interim individually rational. Interim individually rational mechanisms might differ from the ex ante optimal mechanism. The set of implementable in a noncooperative equilibrium set of mechanisms includes all those mechanisms that weakly dominate the least-cost separating mechanism. This set might include mechanisms that are not interim optimal, especially when the the least-cost separating mechanism is not interim optimal. However, I showed that this result is not robust if there are two buyers who can counter-offer mechanisms after the seller makes her offer but before executing the mechanism.

For simplicity, I entirely concentrated on the case in which the buyer has no pri-

vate information. An interesting avenue for future research is to relax this assumption and allow the buyer to possess private information.

\section{REFERENCES}

Akerlof, G.A.: The market for "lemons": Quality uncertainty and the market mechanism. The Quarterly Journal of Economics 84(3), 488-500 (1970)

Balestrieri, F., Izmalkov, S.: Informed seller in a Hotelling market. SSRN (2016) URL https://papers.ssrn.com/sol3/papers. cfm?abstract_id=2398258 
Bulow, J., Roberts, J.: The simple economics of optimal auctions. J. Polit. Econ. 97(5), 1060-1090 (1989)

Cremer, J., McLean, R.P.: Full Extraction of the Surplus in Bayesian and Dominant Strategy Auctions. Econometrica 56(6), 1247-1257 (1988)

Dosis, A.: On signalling and screening in markets with asymmetric information. forthcoming, Journal of Mathematical Economics (2018)

Fleckinger, P.: Informed principal and countervailing incentives. Econ. Lett. 94(2), 240-244 (2007)

Holmstrom, B., Myerson, R.B.: Efficient and durable decision rules with incomplete information. Econometrica 51(6), 1799-1819 (1983)

Jehle, G.A., Reny, P.J.: Advanced Microeconomic Theory, 3rd edn. Pearson Education (2011)

Koessler, F., Skreta, V.: Sales talk. SSRN (2014) URL https://papers.ssrn.com/ sol3/papers. cfm?abstract_id $=2465174$

Mas-Colell, A., Whinston, M.D., Green, J.R.: Microeconomic Theory, vol 1. Oxford University Press, New York (1995)

Maskin, E., Tirole, J.: The principal-agent relationship with an informed principal: the case of private values. Econometrica 58(2), 379-409 (1990)

Maskin, E., Tirole, J.: The principal-agent relationship with an informed principal, II: common values. Econometrica 60(1), 1-42 (1992)

Myerson, R.B.: Optimal auction design. Math. Oper. Res. 6(1), 58-73 (1981)

Myerson, R.B.: Analysis of two bargaining problems with incomplete information. Center for Mathematical Studies in Economics and Management Science, Northwestern University (1983a)

Myerson, R.B.: Mechanism design by an informed principal. Econometrica 51(6), 1767-1797 (1983b) 
Myerson, R.B.: Game theory. Harvard university press (2013)

Myerson, R.B., Satterthwaite, M.A.: Efficient mechanisms for bilateral trading. Journal of economic theory 29(2), 265-281 (1983)

Mylovanov, T., Tröger, T.: Mechanism design by an informed principal: private values with transferable utility. Rev. Econ. Stud. 81(4), 1668-1707 (2014)

Riley, J., Zeckhauser, R.: Optimal selling strategies: when to haggle, when to hold firm. Q. J. Econ. 98(2), 267-289 (1983)

Riley, J.G.: Informational equilibrium. Econometrica 47(2), 331-359 (1979)

Rothschild, M., Stiglitz, J.: Equilibrium in competitive insurance markets: an essay on the economics of imperfect information. Q. J. Econ. 90(4), 629-649 (1976)

Samuelson, W.: Bargaining under asymmetric information. Econometrica 52(4), 995-1005 (1984)

Skreta, V.: On the informed seller problem: optimal information disclosure. Rev. Econ. Des. 15(1), 1-36 (2011)

Spence, M.: Job market signaling. Q. J. Econ. 87(3), 355-374 (1973)

Tan, G.: Optimal procurement mechanisms for an informed buyer. Can. J. Econ. 29(3), 699-716 (1996)

Tisljar, R.: Optimal trading mechanisms for an informed seller. Econ. Lett. 81(1), 1-8 (2003)

Wilson, C.: A model of insurance markets with incomplete information. J. Econ. Theory 16(2), 167-207 (1977)

Yilankaya, O.: A note on the seller's optimal mechanism in bilateral trade with twosided incomplete information. J. Econ. Theory 87(1), 267-271 (1999) 


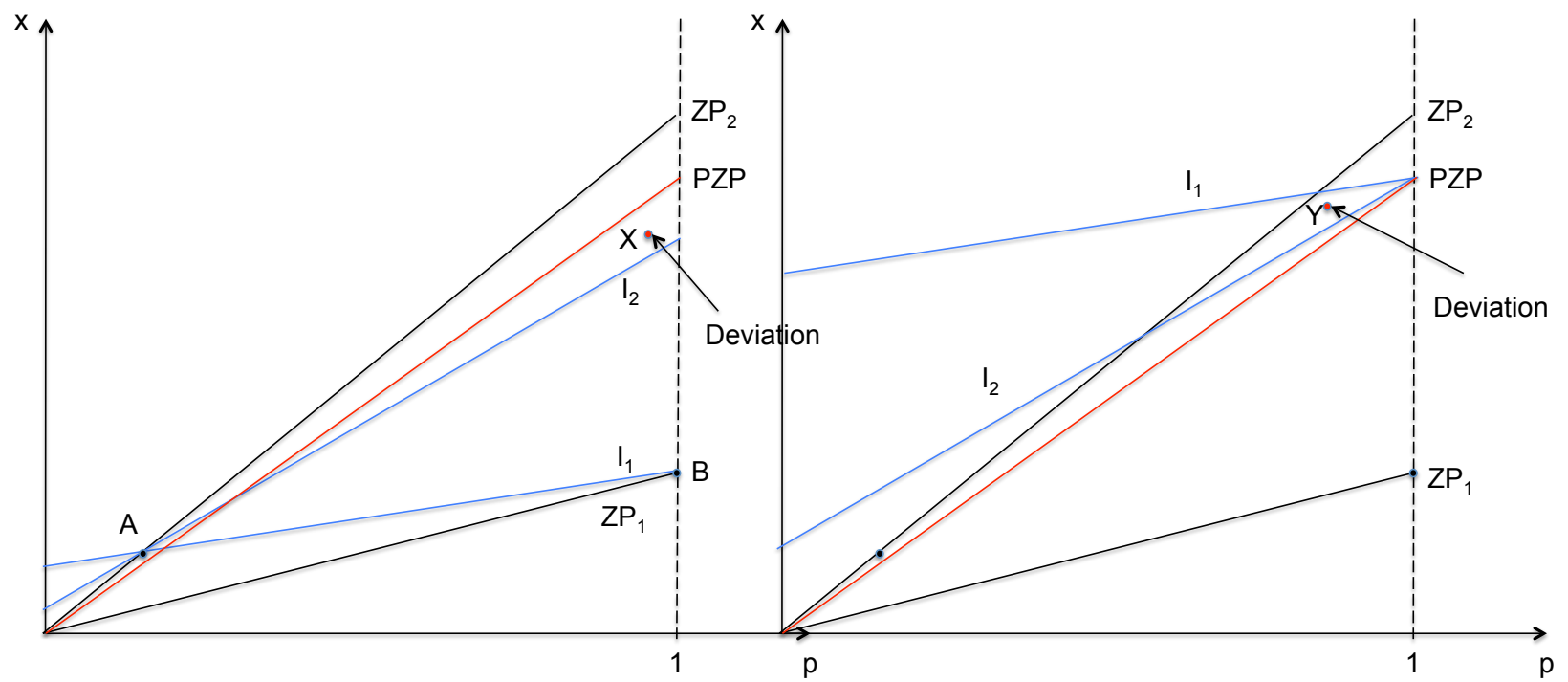

(a)

(b)

Figure 3

\section{Appendix A: THe Buyers COMPETE In Menus}

Suppose that the seller adopts a screening game in which the buyers compete in menus as in textbooks such as Mas-Colell et al. (1995) and Jehle and Reny (2011). These authors consider the following game: there are two stages. In the first stage, each buyer simultaneously and independently offers a menu. In the second stage, the seller selects a contract from at most one buyer. One can easily establish the following proposition:

Proposition 8.1. If the LCS allocation is IO, then it is the unique equilibrium allocation in the screening game. If the LCS allocation is not IO, then an equilibrium in pure strategies does not exist in the screening game.

Therefore, the set of pure-strategy equilibria is a singleton (in terms of payoffs) when the LCS allocation is IO, but it is the empty set when the LCS allocation is not IO. The intuition behind the result is the following. First, one can show that an allocation is an equilibrium allocation only if it is IO. This is the "Bertrand-type" feature of the game. Indeed, for any non-IO allocation, there exists another allocation that results in higher payoff if introduced by the same buyer. Second, when the LCS allocation is IO, an equilibrium can be constructed in which both buyers 
offer this allocation (i.e., menu of contracts) and no buyer can unilaterally deviate profitably. When the LCS allocation is not IO, efficiency entails cross-subsidisation. This situation is depicted in Figure (3a). In this figure, $X$ constitutes a deviation over the LCS mechanism $(A, B)$. One can then show that there exists no equilibrium in which the contract for at least one type makes strictly positive profits. For every such allocation, a profitable deviation exists, as depicted by $Y$ in Figure (3b). A contradiction arises with the first point, and hence, an equilibrium in pure strategies does not exist. 
ESSEC Business School

3 avenue Bernard-Hirsch

CS 50105 Cergy

95021 Cergy-Pontoise Cedex

France

Tel. +33 (0)134433000

www.essec.edu

ESSEC Executive Education

CNIT BP 230

92053 Paris-La Défense

France

Tel. +33 (0)1 46924900

www.executive-education.essec.edu

CONTACT

Centre de Recherche Tel. + 33 (0)134433091

ESSEC Asia-Pacific

5 Nepal Park research.center@essec.fr

Singapore 139408

Tel. +65 68849780

www.essec.edu/asia

ESSEC | CPE Registration number 200511927D

Period of registration: 30 June 2017 - 29 June 2023

Committee of Private Education (CPE) is part of Skillsfuture Singapore (SSG)

\section{ESSEC Africa}

Plage des Nations - Golf City

Route de Kênitra - Sidi Bouknadel (Rabat-Salê)

Morocco

Tel. +212 (0)5 37824000

www.essec.edu 